\title{
Q-Methodology Explained by Comparing Q-Sort Survey with Conventional R-Sample Survey and Relating Factor Analysis Described
}

\author{
Wim Moree * \\ Technische Universiteit Delft, Counsel Contract \& project support at VINCI Energies, Netherlands
}

Submission: July 24, 2017; Published: August 09, 2017

*Corresponding author: Wim Moree, Counsel Contract \& Project Support at VINCI Energies Netherlands, Attorney at law at Corporate Legal Support, PO box 365, 3220, AJ Hellevoetsluis, Netherlands, Tel: 0031-654 765407; Email: mr.w.moree@gmail.com

\begin{abstract}
By applying Q-methodology, subjective opinions and reflections, measured by means of Q-sort survey can systematically be analyzed. This contrary to the use of conventional R-sample survey which is not suitable for measuring subjective opinions and reflections. With the factor analysis method, patterns in the correlation between the measured multiple variables of Q-sort survey can be determined from which distinct patterns of perspectives or opinions can be constructed and across these perspectives shared beliefs can be identified. This article is intended to concisely describe the difference between the use of the conventional R-sample survey and Q-sort survey on the basis of a single variable example and to describe the meaning of factor analysis, loading factor, factor rotation and varimax rotation, as well as factor scores and factor weights as elements of the factor analysis technique..
\end{abstract}

Keywords: Q-methodology; Q-sort, R-sample; Factor analysis; Perspectives; Loading factor; Factor rotation; Varimax rotation

\section{Q-Methodology}

Subjective opinions and reflections can be systematically analyzed by applying Q-methodology. This methodology has been used as the basis of survey in the study 'Sorting out the essence of owner -contractor collaboration in capital project delivery' [1]. This study can serve as a practical example of the application of this methodology.

Q-methodology is an inverted technique of factor analysis (R-method), invented by psychologist -physicist William Stephenson in the 1930s [2] as the basis for a scientific approach to human subjectivity. The method can be used in any research field where subjectivity is at issue, including attitude measurement $[2,3]$. Fundamentally it is a discursive, constructivist approach that combines a strong qualitative dimension with the powerful quantitative tool [4]. Mainly due to the work of Brown [5] and McKeown \& Thomas [6] further developed the principles and procedures of Q-sorting, the Q-methodology has more recently found its way to a wide variety of research areas.

\section{Q-Methodology Approach}

In contrast to R-methodology (which is based on surveys and multivariate factor analysis), Q-methodology identifies respondents' responses within the context of the valuation of all statements presented [7]. typically, respondents are presented with a sample of statements (the Q-set) derived from a population of issues (concourse) around the topic of interest. A number of well-informed respondents (the P-set) are asked to rank-order the statements from their individual points of view. Rather than random sampling (and large sample sizes), Q-methodology relies on a small sample of purposively selected respondents. By sorting the statements respondents give subjective meaning to the Q-set and thus revealing their subjective viewpoint [6]. The respondents' sorting data (the Q-sorts) are then factor analyzed to reveal similarities in viewpoint.

Q-factor analysis is an inversion of the conventional by-item factor analysis [3]. Q-factor analysis correlates persons instead of test items (i.e. by-person factor analysis). If each individual had his own specific preferences (likes and dislikes or agree and disagree), their Q-sorts would not correlate. If, however, significant clusters of correlations exist, they can be factorized and described as common viewpoints, and individuals can be mapped to a particular factor. Q-methodology can thus be used to reveal and describe populations of viewpoints rather 
than populations of people as in conventional factor analysis [5,7-9]. In a study based on Q-methodology, a small sample of respondents is sufficient and selected to represent the breadth of opinion in a target population $[5,10]$.

Q-study starts with the development of a set of statements called the concourse. The concourse is the collection of possible statements that respondents can be made about the subject at hand. The concourse is thus assumed to contain all relevant aspects of all the discourse [9]. Typically, in a Q-study, respondents are presented with a sample of these statements, called the Q-sample or Q-set. In our research, these would be statements about the elements of the research subjects and the relations between the subjects under investigation. Respondents, called the P-set, are asked to rank-order the statements from their individual perspective, according to preference, judgment or feeling about them. This P-set would in our research be the persons that are interviewed; the project managers from both sides. This is called Q-sorting.

By Q-sorting people give their subjective meaning to the statements, thus revealing their personal viewpoint [11] or personal profile [12]. These individual rankings on views are subsequent subject to factor analysis. Correlation between personal profiles based on this analysis may than reveal the existence of similar viewpoints or segments of subjectivity [13]. By correlating people, Q-factor analysis provides insight into similarities and differences in viewpoints on a particular subject. A crucial basis of Q-methodology is that subjectivity is communicable, because only when subjectivity is communicated, when it is operational expressed, it can be systematically analyzed just as any other behaviour [2,14].

Q-analysis as part of the Q-methodology does not need large numbers of subjects as R-analysis does, because it can reveal characteristics independent of distribution of that characteristic relative to other characteristics $[9,11]$. It only requires sufficient subjects to establish the existence of a factor for purposes of comparing one factor with another [15].

As Q-sort studies are designed to sample from a concourse of perspectives, rather than from a population of people, representativeness does not depend on large samples of respondents $[7,16]$. For this, the diversity of the respondents is more important than the number of respondents. All the method

Table 1: Conventional R-sample survey.

\begin{tabular}{|c|c|c|c|}
\hline \multicolumn{3}{|c|}{ Length Distribution Urban Village Sample } \\
\hline Length Classification & Frequency & \multicolumn{2}{|c|}{ Results } \\
\hline 145 & 2 & total sample size & no of length classes \\
\hline 155 & 15 & average length & average deviation \\
\hline 165 & 55 & & 20 \\
\hline 175 & 80 & 55 & \\
\hline
\end{tabular}

requires is sufficient respondents to identify these perspectives as factors to make it possible to compare among factors [5]. Most Q-sort studies result in less than seven factors, and often not more than two or three. For purposes of identification of factors only four or five respondents are required to produce stable factors $[6,7]$.

Summarized a Q-methodology study can be based on four steps.

a. Firstly, by formulating Q-samples (samples of population of opinion), the actual research instrument and the basis of any Q methodological study.

b. Secondly, by conducting Q-sorting sessions with samples of respondents.

c. Thirdly, by factor analyzing all Q-sorts data to reveal the distinct perspectives. Ultimately, the results of factor analysis were interpreted to reconstruct and make sense of the revealed distinct practitioners' perspectives on ways to improve owner-contractor relationship.

\section{Q-Sort Survey Compared with Conventional R-Sample Survey}

Suppose you want to align the height of the doors in the design of new homes in Urban Village with the length of the residents of Urban Village. Such design could be based on the mean length of Urban Village residents between 18 and 65 years of age and the average (standard) deviation of their mean length. The height of the doors could for instance be specified as equal to the mean length of these residents, increased with (as an assumption) $2 \mathrm{x}$ the average (standard) deviation of their mean lengths.

\section{Conventional R-sample survey}

For this purpose, you can perform a conventional sample survey in which you measure the variable length of a random sample of the target group of residents. To be able to determine the mean length (and deviation) of the residents in the target group by virtue of that sample with a reasonable reliability a quite large sample of the target population is needed. Such a sample requires a number of persons in the magnitude of a hundred or more. The frequency distribution of the results from that sample will almost form a normal distribution (Table 1) (Figure 1). 


\section{Civil Engineering Research Journal}

\begin{tabular}{|c|c|c|c|}
\hline 195 & 15 & average length+ average deviation & 195 \\
\hline 205 & 2 & $\begin{array}{c}\text { average length+2 x average } \\
\text { deviation }\end{array}$ & 215 \\
\hline
\end{tabular}

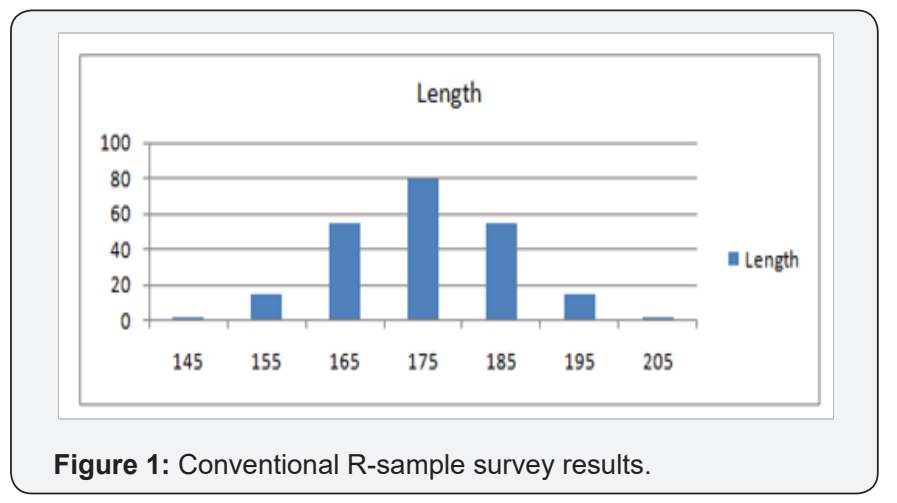

Above, an example of the results of such a survey is given. Based on its results the design height of the doors would be 215 $\mathrm{cm}$ in which is the mean length of $175 \mathrm{~cm}$ plus $2 \mathrm{x}$ the average

Table 2: Random order to the 7 selected residents.

\begin{tabular}{|c|c|c|c|c|c|c|c|c|c|c|c|c|c|c|c|c|c|c|c|}
\hline \multicolumn{20}{|c|}{ Q-Statements of Door Heights on 20 Sort Cards } \\
\hline 160 & 165 & 170 & 175 & 180 & 185 & 190 & 195 & 200 & 205 & 210 & 215 & 220 & 225 & 230 & 235 & 240 & 245 & 250 & 255 \\
\hline
\end{tabular}

To the selected persons, cards are presented with on each card a different door height, ascending with $5 \mathrm{~cm}$ from $160 \mathrm{~cm}$ to $255 \mathrm{~cm}$. So, amongst these cards there will be one card on which the design height of $215 \mathrm{~cm}$ from the example is stated, which is based on the results of the conventional survey. In this example, there are a total of 20 cards with statements on the door heights. They are referred to as Q-statements. These cards are presented individually in random order to the 7 selected residents (Table 2). For each card, the resident must answer to what level he agrees with the following statement: 'Considering a door with this height, I believe that this is the optimal height for a door in an average family home at Urban Village'.

First, he should answer this question with: 'agree', 'disagree' or 'neutral', and place the cards on 3 corresponding piles. Then he distributes the cards of each pile on corresponding area for 'agree', 'disagree' or 'neutral' in a more detailed ranking on a Q-sort distribution board with has as many boxes as there are cards. This can even be supported by having these persons experience the different doorways by leading them through models of these doorways.

The boxes on the distribution board are distributed over a range of -3 to +3 in an approximate normal distribution, ranging from 'most disagree' to 'most agree'. By doing so, for each selected resident the cards are distributed on the board such that on the right-hand side of the board the cards with the door heights that are most appreciated are positioned. On the most right-hand position the card with the perceived optimal door (standard) deviation there of of $20 \mathrm{~cm}$. What you don't know is whether potential buyers of these homes, being the target group, would experience the height of the designed doors as optimal. So, it could be that the height of the doors based on the mean length plus $1 \mathrm{x}$ the average (standard) deviation on the mean length would match better with their subjective expectations than based on $2 \mathrm{x}$ this deviation $[17,18]$.

\section{Q-sort survey}

Q-sort survey is an appropriate method to investigate such subjective perception. For the purpose of such a survey, you should select at least one resident of each length class from the target group of residents. In this example, there are 7 people. As described above, it has been scientifically established that already with such a sample of research units, reliable results can be generated with this method.

height is positioned. This distribution is the individual Q-sort. The 7 individual Q-sorts are then compiled into a resulting Q-sort distribution. This resulting distribution represents a quasi (near normal) Q-sort distribution in which the influence of each individual Q-sort distributions is represented best. The statement on the most right-hand position of this resulting Q-sort indicates the door height that is perceived as the most optimal height for a door in average home in Urban Village.

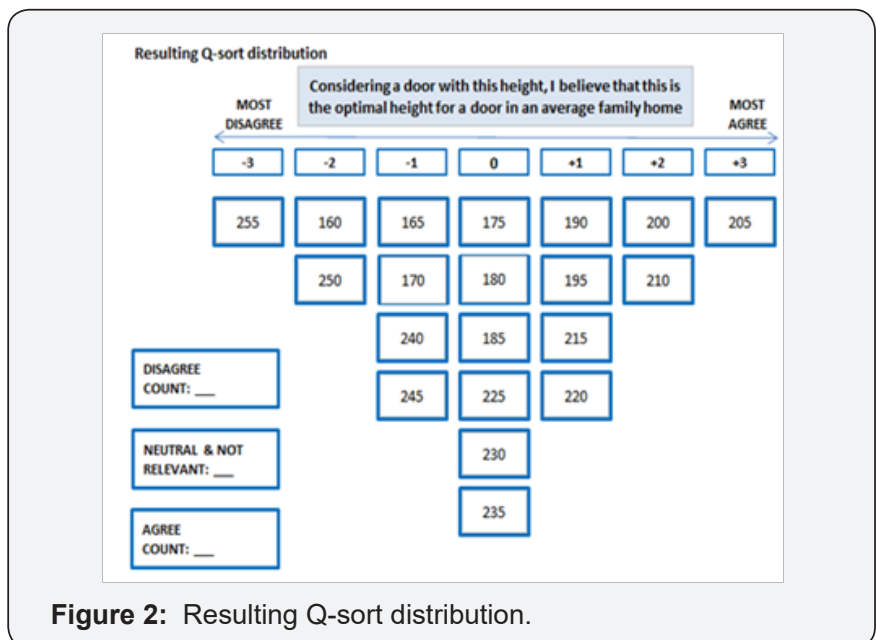

Below, example is given of the resulting Q-sort distribution of such a Q-sort survey. Based on its results, the design of the height of the doors that would be perceived as most optimal by the target group of residents would be $205 \mathrm{~cm}$. Considering the results of the conventional survey, the door height should be 
based on the mean length of the target residents group plus 1.5 $x$ average (standard) deviation on their mean length instead of the plus $2 \mathrm{x}$ as used as the design basis in the example (Figure 2).

\section{Factor Analysis}

The example described above is based on the research of one variable, but most surveys include more. An example of a research including more variables could be the research on the statements in an election manifesto of a political party. Suppose you want to know which statements in such an election manifesto are strongest interrelated.

For this purpose, you can perform a conventional survey among a sample of a randomly selected number of voters in the target group whom you ask their opinions on statements in the election manifesto. From the results, you can infer how the statements relate to each other, but the results do not provide insight into which combination of statement is perceived by the voters as most optimal. Q-sort survey is an appropriate method to investigate such a subjective perception. If you want to know how these variables are related, the best approach is to first calculate the correlation between the variables. However, if there are many variables, it may become difficult to determine a clear pattern in the correlation. In such case, factor analysis is the recommended analysis technique.

Factor analysis is a method by which one or more new factors (or dimensions) are constructed based on a number of measured variables. The aim of the analysis is to obtain insight into the structure of the data by reducing the number of variables. To enable this, a smaller number of new underlying variables called 'factors' are constructer, based on the correlation between a large numbers of the original variables. Therefore, the question is to which extent this large number of original variables is related to this smaller number of factors. A commonly used method is to let the analysis program decide about the number of factors and which variables are most heavily 'loaded' on these factors (explorative factor analysis). The basis of factor analysis is the correlation matrix of the measured variables. There are two methods: Q-factor analysis and R-factor analysis.

\section{Q-factor analysis}

With Q-analysis you analyze the correlation between the research units (respondents) across the variables. The question is which research units are strongly similar to each other in view of the score pattern on the variables. In our example, the research units are the represented voters in the sample and the variables are the statements in the election programs. The Q-factors are the most associated views of the respondent's on combinations of statements in the election program. The basis for this analysis is the correlation matrix between research units, which are the represented voters in the sample (the respondents).

\section{R-factor analysis}

In R-analysis, in contrast, you analyze the correlation between the variables across the research units. The question than is which variables are very similar in view of their score pattern across the research units. In this case, the basis is formed by the correlation matrix between the variables. In our example, the R-factors are the most associated statements in the election program across the represented voters in the sample. $\mathrm{R}$-analysis is primarily used because there are usually many more research units (in our example represented voters) than variables (election statements).

\section{Loading factor}

The correlation between the variable and the factor is defined as the loading of the variable on the factor. A high loading means that the relevant factor is important for the variable. You can instruct the computer program for the factor analysis to construct the various factors in such a way that they do not have any mutual correlation. In that case, the factors are said to be orthogonal, which means at right angles to each other, independent. The most conventional way to extract the factors is by using the principle component method.

\section{Factor rotation, varimax rotation}

You can consider the orthogonal factors as the $\mathrm{x}$ - and $\mathrm{y}$-axes in a set of coordinates. By using the loadings, the variables can be drawn on that set of coordinates. Frequently it is necessary to first rotate the factors, which means choosing other axes, to be able to interpret the figure. By using rotation, one tries to provide a variable with a significantly high loading on a single factor and provide a low loading on the other factors. This makes it easier to explain that principle factor. The most commonly used method is the Varimax rotation, whereby the orthogonality of the factors is conserve

\section{Factor scores}

The following step is to describe the research units for which you have measured the variables in terms of the factors that are found. Than calculate the scores of the research units on the new factor. The results are the factor scores.

\section{Factor weights}

Since a factor is constructed from a specific combination of variables (for R-analysis) or research units (for Q-analysis), a factor score is the linear combination of the original variables or research units. Here, linear means that the only possible valid operations are additions and subtractions. When adding or subtracting, each variable is given its own coefficient (weight), which indicates how heavily the variable should weigh when calculating the factor score. 


\section{Civil Engineering Research Journal}

\section{References}

1. Suprapto M, Bakker LM, Mooi HG, Moree W (2014) Sorting out the essence of owner-contractor collaborationin capital project delivery. International Journal of Project Management.

2. Stephenson W (1953) The Study of Behaviour: Q-technique and Its Methodology. University of Chicago Press, Chicago, USA

3. Stephenson W (1965) Perspectives in Psychology: XXIII Definition of Opinion, Attitude and Belief. The Psychological Record 15(2): 281-288.

4. Stenner P, Watts S, Worrell M (2008) Q Methodology. In: Willig C, Stainton-Rogers W (Eds.), The SAGE Handbook of Qualitative Research in Psychology. Sage Publications Ltd, London, England, pp. 215-239.

5. Brown SR (1980) Political Subjectivity: Applications of Q Methodology in Political Science. Yale University Press, New Haven, USA.

6. McKeonn B, Thomas D (1988) Q methodology. Sage, Newbury Park, California, USA.

7. Ten Klooster PM, Visser M, De Jong MDT (2008) Comparing two image research instruments: The Q-sort method versus the Likert attitude questionnaire. Food Quality and Preference 19 (5): 511-518.

8. Cross RM (2005) Exploring attitudes: the case for Q methodology. Health Educ Res 20(2): 206-213.

9. Van Exel NJA, De Graaf (2005) Q methodology: A sneak preview.
10. Brown SR (1996) Q methodology and qualitative research. Qual Health Res 6(4): 561-567.

11. Smith NW (2001) Current systems in psychology: history, theory, research and applications. The Psychological Record 51(3): 495-497.

12. Brouwer M (1999) Q is accounting for tastes. Journal of Advertising Research 39(2): 35-39.

13. Brown SR (1993) A Primer on Q methodology. Operant Subjectivity 16(3-4): 91-138.

14. Stephenson W (1968) Perspectives in psychology: consciousness out subjectivity in. Psychol Rec 18(1): 499-501.

15. Militello M, Benham KP (2010) Sorting Out collective leadership: How Q-methodology can be used to evaluate leadership development. The Leadership Quarterly 21: 620-632.

16. Anderson C, Avery PG, Pederson, PV, Smith ES \& Sullivan JL (1997) Divergent perspectives on citizenship education: A Q-method study and survey of social studies teachers. American Edu Resh J 34(2): 333364.

17. Stephenson W (1935) Correlating persons instead of tests. Character and Personality 4(1): 17-24.

18. Van der Velde M, Jansen P, Anderson N (2007) Guide to Management Research Methods. Oxford, UK: Blackwell Publishing, USA, pp. 1-264.

\section{Your next submission with Juniper Publishers} will reach you the below assets

- Quality Editorial service

- Swift Peer Review

- Reprints availability

- E-prints Service

- Manuscript Podcast for convenient understanding

- Global attainment for your research

- Manuscript accessibility in different formats

( Pdf, E-pub, Full Text, Audio)

- Unceasing customer service

Track the below URL for one-step submission https://juniperpublishers.com/online-submission.php 